\title{
ANALYSIS OF BOUNDARY CONDITIONS FOR THE SIMULATION OF WELDING AT THE REPAIR OF GAS PIPELINES WITH STEEL SLEEVE
}

Theoretical part of the manuscript deals with basic information about repair of gas pipeline with steel repair sleeves and simulation programme SYSWELD. Experimental part includes analysis of boundary conditions in two-pass fillet welding joint. Results of the analysis will be used for simulation in simulation programme SYSWELD.

Keywords: Steel repair sleeves, L360NB, SYSWELD.

\section{Introduction}

The article deals with the issues of repairing defects at steel gas pipes, in particular of permanent repairs with using steel sleeves.

\section{Theoretical part}

\subsection{Permanent repair of defects at gas pipelines with using steel sleeves}

The Steel Repair Sleeves can be used for permanent repairing of high pressure gas, pipeline defects without interrupting. With using these repair methods, we can repair defects, such as internal and external corrosion, gouges, dents, grooves, arc burns, cracks, defective girth welds, laminations and leaks [1].

The steel sleeve is composed of segmented steel casing, fitted on two steel distance rings, which defines the space between the sleeve and the repaired pipe. This space is filled with glass beads and epoxy (composite). Cured epoxide, provides a perfect transmission of stresses from pipeline to sleeve. Type of material and thickness sleeve and distance rings, must be same as the thickness of the repaired pipeline. Epoxy obtains desired mechanical properties after 24 hours curing. Good space filling composites are checked through the inspection holes [1].

Depending on the seriousness and type of defect on the pipeline sleeves can be divided to:

- cold sleeve - steel casing fitted on two steel distance rings is welded only longitudinal butt weld,

- hot sleeve - steel casing fitted on two steel distance rings is welded longitudinal butt weld and also is welded with fillet weld to distance rings [1].
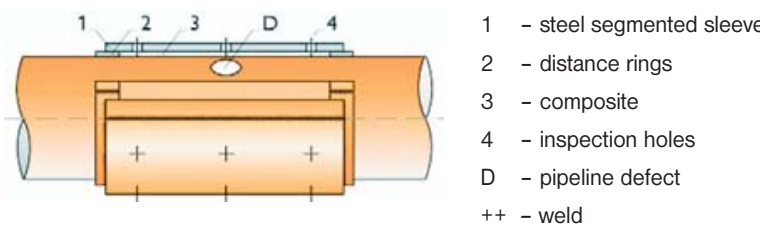

Fig. 1 Steel repair sleeve [1]

\subsection{SYSWELD}

SYSWELD is a Finite Element software that simulates all usual welding processes such as MMA, MIG, TIG, spot welding, laser welding, heat treatment like bulk hardening, surface hardening, tempering and hardening and tempering, as well as thermo-chemical treatment like case hardening, carbonitriding, nitriding [2].

The software calculates dimensional variations and distortions of parts, hardness, strength and strain at break of the material in use, plus residual stresses, during and at the end of the welding or heat treatment process [2].

Simulation of a welding process requires two successive analyses:

- first a thermo-metallurgical analysis,

- followed by a mechanical analysis.

\subsubsection{Definition of heat source in SYSWELD}

Temperature $T(x, y, z, t)$ is function of coordinates in volume and time. Precious determination of temperature field during welding

\footnotetext{
* Radoslav Konar, Milos Mician, Anton Hopko

Department of Technological Engineering, Faculty of Mechanical Engineering, University of Zilina, Slovakia,

E-mail: radoslav.konar@fstroj.uniza.sk
} 
(that means mainly shape and size of heat affected zone) is firs and very important step for real determination of right material structure. Therefore finding the right mathematical description for heat source is very important for numerical simulations.

Simulation system SYSWELD used for numerical calculations of heat following heat sources: 2D Gaussian model - for surface thermal treatment of material, 3D Gaussian model - for simulation of welding with high power density in impact area and 3D Glodak model - for shielded metal arc welding, submerged arc welding, GTAW, GMAW. Just because of great using variability will be this type of heat source closely described [3].

\subsubsection{Goldak model of heat source}

This type of heat source can be used for most of fusion welding conventional methods. Combination of two interlocking ellipsoids describes best real state so far. By contrast to previous heat source is double-ellipsoid heat source described by two equations individually for each ellipsoid. Compared to ellipsoid heat source there are in following equations parameters $f_{1}$ and $f_{2}$. These are constants which influence energy flow intensity into material (into individual ellipsoids) and for them the following equation has to be valid:

$$
f_{1}+f_{2}=2
$$

Double-ellipsoid heat source is shown in Fig. 2 and is described by following equations (2) and (3).

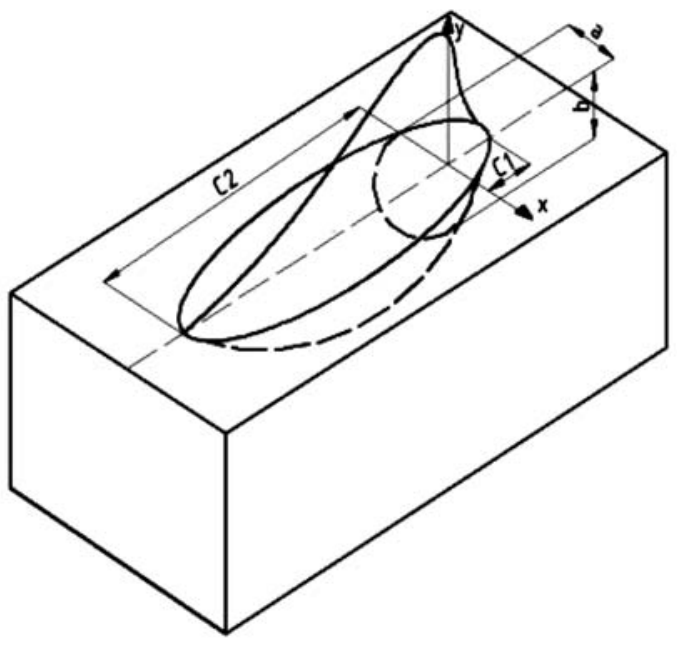

Fig. 2 Goldak double ellipsoidal heat source model [3]

$$
\begin{aligned}
& q(y, x, \xi)=\frac{6 \cdot \sqrt{3} \cdot f_{1} \cdot Q \cdot \eta}{a \cdot b \cdot c_{1} \cdot \pi \cdot \sqrt{\pi}} \cdot e^{\frac{-x^{2}}{a^{2}}} \cdot e^{\frac{-y^{2}}{b^{2}}} \cdot e^{\frac{-\xi^{2}}{c_{1}^{2}}} \\
& q(y, x, \xi)=\frac{6 \cdot \sqrt{3} \cdot f_{2} \cdot Q \cdot \eta}{a \cdot b \cdot c_{2} \cdot \pi \cdot \sqrt{\pi}} \cdot e^{\frac{-x^{2}}{a^{2}}} \cdot e^{\frac{-y^{2}}{b^{2}}} \cdot e^{\frac{-\xi^{2}}{c_{2}^{2}}}
\end{aligned}
$$

Where location of heat source is given by equation:

$$
\xi=z_{k}-v \cdot(\tau-t)
$$

where:

$q(x, y, \xi)$ - heat flow density into material, [W. $\left.\mathrm{m}^{-3}\right]$

$Q \quad$ - overall heat, [W]

$a, b, c_{1,2}$ - coordinates of fusion zone, [m]

$x, y, z \quad$ - coordinates of point, [m]

$f_{1}, f_{2} \quad$ - constants influencing energy flow intensity distribution into material, [-]

$\eta \quad$ - heat source efficiency, [-]

$\tau \quad$ - overall welding time, [s]

$t \quad$ - instantaneous welding time, [s]

- welding velocity, $\left[\mathrm{m} . \mathrm{s}^{-1}\right]$

$\xi \quad$ - location of heat source in dependence on welding time, [m]

$z_{k} \quad-$ z-coordinate at the close of welding [3].

\section{Experimental part}

This experiment includes analysis of boundary conditions for the simulation of welding in the repair of gas pipelines with steel sleeve.

\subsection{Experimental sample}

Model used for the experiment was compounded of two $60^{\circ}$ pipe sections of materials L360NB (pipe and distance ring). Pipe has a diameter of $323.9 \mathrm{~mm}$, pipe's thickness is $10 \mathrm{~mm}$ and length $260 \mathrm{~mm}$. Distance ring has a diameter of $333.9 \mathrm{~mm}$, ring thickness $10 \mathrm{~mm}$ and length $90 \mathrm{~mm}$. Welding joint was welded using the MMA process. Experimental sample was welded with two fillet passes of weld. These two layers are only part of the finished weld.

\subsection{Experimental measurements during and after welding}

During welding were measured welding parameters, welding time and thermal cycles in three points. After welding the weld was analysed. Complete analysis of the weld for simulation in simulation programme SYSWELD contains:

Parameters of welding

Tab. 1.

\begin{tabular}{|c|c|c|c|c|}
\hline \multicolumn{5}{|c|}{ Parameters of welding } \\
\hline Weld & $U_{w}[\mathrm{~V}]$ & $I_{w}[\mathrm{~A}]$ & $s_{w}\left[\mathrm{~mm} \cdot \mathrm{s}^{-1}\right]$ & $Q_{r}\left[\mathrm{~J} . \mathrm{cm}^{-1}\right]$ \\
\hline Weld 1 & 23.6 & 92 & 2.2 & 7895 \\
\hline Weld 2 & 23.6 & 92 & 2.25 & 7719 \\
\hline
\end{tabular}

$U_{w}$ - welding voltage $\quad s_{w}$ - welding speed

$I_{w}$ - welding current $\quad Q_{r}$ - real heat input $(\eta=0.8)$ 

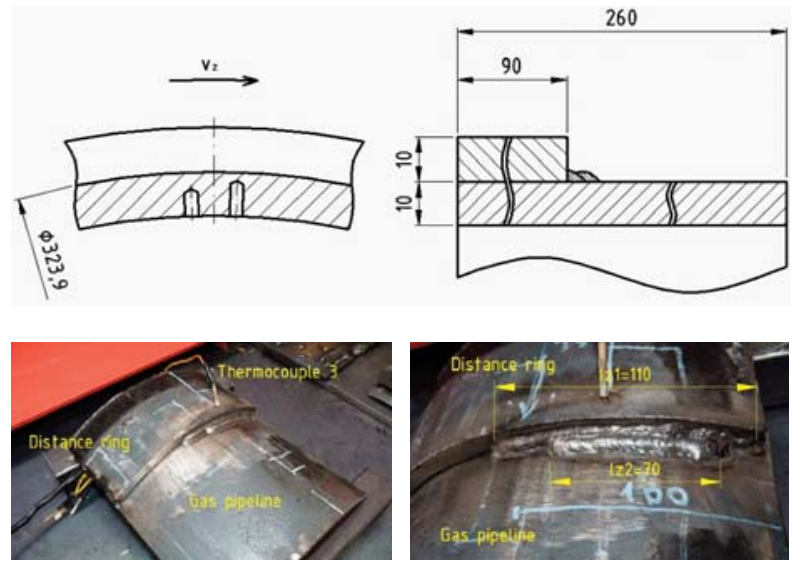

Fig. 3 Experimental sample, scheme (up), real sample (down)

- parameters of welding $\left(U_{w}, I_{w}\right)$,

- cross-sectional geometry of the welds (weld metal, heat affected zone),

- welding speed $\left(s_{w}\right)$,

- thermal cycles.
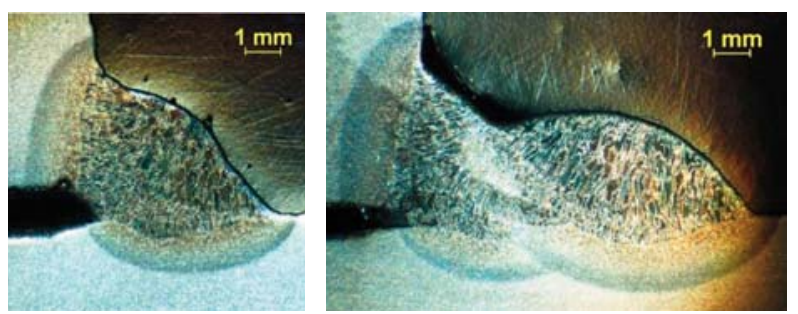

Fig. 4 Macrostructural analysis

Digitizing the weld macrostructures, we get cross-sectional parameters of welds (Fig. 5.), which are necessary for the definition of Goldak heat source model.
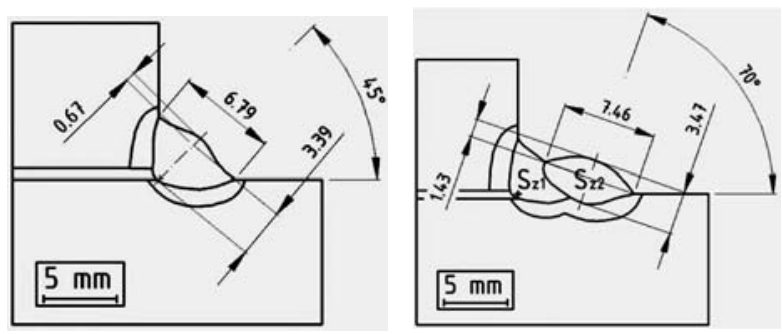

$S_{z 1}=17,2 \mathrm{~mm}^{2}$ - weld area $S_{z 2}=16 \mathrm{~mm}^{2}$

Fig. 5 Cross-sectional parameters of the weld

Temperature cycles were measured by three thermocouples. Their location is shown in Fig. 6.

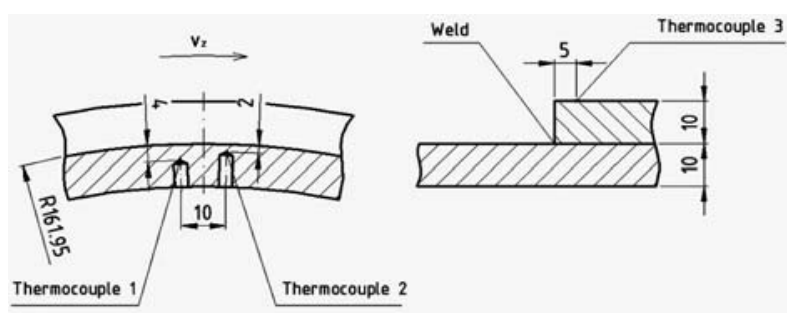

Fig. 6 Location of thermocouples

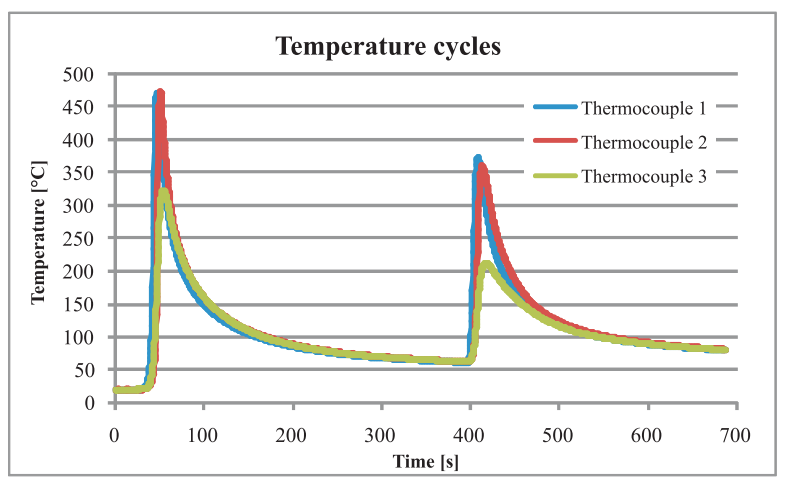

Fig. 7 Temperature cycles in three thermocouples

Characteristic attributes of temperature cycle

Tab. 2.

\begin{tabular}{|c|c|c|c|}
\hline \multicolumn{4}{|c|}{ Characteristic attributes of temperature cycles } \\
\hline \multicolumn{4}{|c|}{ 1. pass of weld } \\
\hline Thermocouple & $T_{\max }\left[{ }^{\circ} \mathrm{C}\right]$ & $r 300\left[{ }^{\circ} \mathrm{C} . \mathrm{s}^{-1}\right]$ & $t 100[\mathrm{~s}]$ \\
\hline 1. & 465 & 9.78 & 113 \\
\hline 2. & 480 & 10.6 & 117 \\
\hline 3. & 322 & 6.5 & 112 \\
\hline \multicolumn{4}{|c|}{2. pass of weld } \\
\hline Thermocouple & $T_{\max }\left[{ }^{\circ} \mathrm{C}\right]$ & $r 300\left[{ }^{\circ} \mathrm{C} . \mathrm{s}^{-1}\right]$ & $t 100[\mathrm{~s}]$ \\
\hline 1. & 373 & 8.7 & 136 \\
\hline 2. & 360 & 8.5 & 144 \\
\hline 3. & 212 & - & 126 \\
\hline
\end{tabular}

\section{Conclusion}

Experimental results will serve as a boundary condition for the simulation in simulation programme SYSWELD. The simulation process will provide information about residual stresses arising in the repair of gas pipelines with steel sleeve.

\section{Acknowledgement}

This work has been supported by the Scientific Grant Agency of the Ministry of Education of the Slovak Republic, grant VEGA No V-08-046-00. 


\section{References}

[1] PARIZEK, P., BRYNYCH, A., STUKBAUER, M.: Permanent Repairs of Steel Pipes in Operation with the Help of Sleeves and Wraps (in Czech). In Plyn. vol. LXXXVI., online: http://www.ceps-s.cz/download/Opravy-ocelovych-potrubi-bez-preruseni-provozu-aplikaciobjimek_PLYN_2006-11.pdf, 2006.

[2] MORAVEC, J.: Simulation of Fusion Welding - Simulation Programme SYSWELD (in Czech). In Zvarac. ISSN 1336-5045, vol. VI, 2/2009, p. 9-12.

[3] MORAVEC, J., SOBOTKA, J., BRADAC, J.: Numerical Simulations Utilization for Welding Hardly Weldable Materials Based on Iron Aluminides. Technical university of Liberec, 1. ed., 2010. ISBN 978-80-7372-682-9, 2010. 